\title{
The evaluation of phenotyping and molecular resistance to antibiotics in Proteus species isolated from urinary tract infections in Ilam city
}

\author{
Arman Rostamzad $^{1 *}$, Khadijeh Fattahi ${ }^{1}$, Mostafa Nemati ${ }^{2}$
}

1. Department of Biology, Faculty of Science, Ilam University, Ilam, Iran

2. Department of Bacteriology, Para Veterinary Faculty, Ilam University, Ilam, Iran

*Corresponding author:Tel: +98 9188412905 Fax: +98 8432227022

Address: Department of Biology, Faculty of Science, Ilam University, Ilam, Iran

E-mail: arostamzad381@yahoo.com

Received: 2015/10/25 revised: 2015/11/22 accepted: 2016/01/6

\begin{abstract}
Introduction: Resistance of pathogenic organisms to countenance antibiotics has become a worldwide problem with serious consequences on the treatment of infectious diseases. The aim of this study was to evaluate antibiotic resistance and also the detection of transferred antibiotic resistance by plasmid in clinical Proteus isolates.
\end{abstract}

Materials and methods: A total of 250 urine samples were collected from patient suffered from urinary tract infection (UTI), and cultured on blood agar and MacConkey's agar. Positive cultures were diagnosed by routine microbiological and biochemical tests. Antibiotic susceptibility test was performed by disc diffusion method. The minimum inhibitory concentration (MIC) was evaluated by agar dilution method, and also antibiotic resistance mediated by plasmid was determined using transformation of plasmids to plasmid free Escherichia coli ATCC 25922 as competent cell.

Results: Among 200 samples, 120 samples (60\%) were collected from female and 80 samples (40\%) were isolated from males. Out of 25 species $(12.5 \%)$ were diagnosed as Proteus. Al isolates were resistant to ampicillin (maximum frequency), only $16 \%$ of isolates were resistance to amikacin (minimum resistance). Totally, $66.66 \%$ of Proteus isolates harbored plasmids. All plasmid containing P. mirabilis isolates were able to transferred resistance to amoxicillin, ampicillin, while rate of resistance to other antibiotics were as amikacin (88\%), gentamycin (72\%), tetracycline (50\%), tobramycin (48\%), ceftazidime, cefotaxime $(32 \%)$ and ciprofloxacin $(22 \%)$.

Conclusion: Widespread use of antibiotics cause to spread or emerge antibiotic resistances among bacteria by R-plasmids transfer.

Keywords: Proteus, Urinary tract infections, Antibiotic resistance, Plasmid transformation

\section{Introduction}

Proteus, gram-negative bacilli that thrive in soil, water and the intestinal tracts of mammals, is capable of swarming or swimming in a coordinated manner, on solid surfaces. Several species of Proteus species are known to colonize and infect the human host, but, the one most frequently linked with causing human disease is Proteus mirabilis. These bacteria are the causative agents of a variety of opportunistic nosocomial infections including those of the respiratory tract, eye, ear, nose, skin, burns, throat and wounds (1). Proteus mirabilis is more commonly associated with urinary tract infection, individual with structural or functional abnormalities, especially ascending infections in patients undergoing urinary catheterization (2). Proteus species are among the commonly implicated pathogens in hospital as well as community acquired infections (3).Strains are intrinsically resistant to bacitracin, colisitin and polymyxin and are generally susceptible to 
aminoglycosides, cephalosporins, nalidixicacid and penicillin. However, resistance to these antibiotics and or others are currently reported at increasing frequency; a phenomenon which usually results in difficult treatment and control of P. mirabilis infections (4). Mechanisms of resistance of $\mathrm{P}$. mirabilis are plasmid and chromosomal-mediated. There are many mechanisms were by bacteria confer resistance to the drugs including intrinsic impermeability and acquired resistance as plasmids, transposons and mutations (5). Transferable resistance has been identified for some antibiotic groups as $\beta$-lactams, aminoglycosides, macrolides, sulphonamides, tetracycline, chloramphenicol, etc. (6). This study aimed to determine of susceptibility patterns and the evaluation of phenotyping and molecular (plasmid transfer) resistance to antibiotics in Proteus isolated from urinary tract infection in Ilam

\section{Materials and methods}

Sample collection: A total of 200 primary culture positive samples which were collected from hospitalized cases of UTI of two hospitals from Ilam. All samples were transported to clinical microbiology research in Ilam university and were stored frozen at $-80 \mathrm{C}$ in Skim Milk broth, containing $10 \%$ glycerol (7).

Diagnosis of isolates: The samples were collected in a one year period from September 2012 to September 2013. Specimens were screened by Gram's stain and were cultured on $10 \%$ sheep blood agar and MacConkey's agar. All isolates were identified by catalase production, haemolysis on blood agar, oxidativefermentative test, motility, Methyl red (MR) test, Vogex-Proskauer test (VP), citrate utilization test, triple sugar iron (TSI), produced $\mathrm{H} 2 \mathrm{~S}$, production of bound and free coagulase, mannitol fermentation and 7.5 percent $\mathrm{NaCl}$ tolerance and heat labile DNase, protease on skim milk, amylase, protease on gelatin, urease, nitrate reductase, and indole production (8).

Antibiotics susceptibility test: Antibiotic susceptibility test was performed by Kirby Bauer disc diffusion method on MuellerHinton agar and minimum inhibitory concentrations(MICs) of all antibiotics were determined by agar dilution methods according to Clinical and Laboratory Standards Institute recommendations (CLSI, 2007). The following antibiotics were tested: Ampicillin $(10 \mu \mathrm{g})$, Cotrimoxazole $(25 \mu \mathrm{g})$, Gentamycin $(10 \mu \mathrm{g})$, Ciprofloxacin $(10 \mu \mathrm{g})$, Cefotaxime $(30 \mu \mathrm{g})$, ceftazidime $(30 \mu \mathrm{g})$, tetracycline $(30 \mu \mathrm{g})$, tobramycin $(10 \mu \mathrm{g})$, Amoxicillin $(10 \mu \mathrm{g})$,

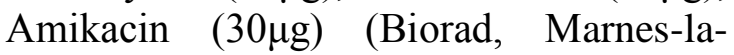
coquette, France). The diameter of zone of growth-inhibition observed was measured and compared according to recommendations of CLSI guidelines. E. coli ATCC 25922 was used as negative control (10).

Plasmid DNA extraction: All proteus isolates were selected for plasmid extraction and determination of plasmid mediated resistant. Briefly a fresh colony of all proteus isolates were cultured in LB medium and incubated at $37^{\circ} \mathrm{C}$ overnight and their turbidity adjusted to 0.5 McFarland standards, and $1 \mathrm{ml}$ of each isolates were cultured in $5 \mathrm{ml}$ tubes containing LB medium and incubated overnight at $37^{\circ} \mathrm{C}$ for plasmid isolation. Plasmid DNA extraction and purification was carried out using YTA Miniprep Kit (Yekta Tajhiz Azma Co, Tehran, Iran), according to the manufacturer's instructions .

Agarose gel electrophoresis: The purity of plasmid was evaluated at $260 \mathrm{~nm}$ by spectrophotometery. The plasmid DNA was observed by gel electrophoresis. To prepare the gel, Agarose gel powder $(0.8 \%)$ was dissolved in TAE buffer (40 Mm Tris$\mathrm{Hcl}, 50 \mathrm{mM}$ Sodium acetate, $1 \mathrm{Mm}$ EDTA; $\mathrm{pH} 8$ ). The extracted DNA was added to the gel and the Gel was run for two and half hours at $50 \mathrm{~V}$, stained for $30 \mathrm{~min}$ with ethidium bromide $(0.5 \mu \mathrm{g} / \mathrm{mL})$. The 
plasmids were visualized under UV light in Alpha imager gel documentation system (Syngene, UK).

Preparation of competent cells: A fresh colony of E.coli ATCC 25922 was cultured in $5 \mathrm{ml} \mathrm{LB}$ broth and incubated at $37^{\circ} \mathrm{C}$ overnight in shaker incubator at round 250rpm, Then inoculate $5 \mathrm{ml}$ of overnight culture into a flasks containing $500 \mathrm{ml} \mathrm{L}$ broth, and incubated at $37^{\circ} \mathrm{C}$ with aeration until the culture reaches OD550 of 0.5 (approximately $5 \mathrm{x}$ 107cells $/ \mathrm{ml}$ ) Transferred cells to centrifuge bottles and spin in Sorvall GSA rotor at $4^{\circ} \mathrm{C}$ for $8 \mathrm{~min}$ at $8000 \mathrm{rpm}$. The supernatant discarded and gently resuspended pellets in $250 \mathrm{ml}$ ice cold $0.1 \mathrm{M} \mathrm{CaCl} 2$ and combined into a single bottle, then spine $8 \mathrm{~min}$ at $8000 \mathrm{rpm}$ in GSA rotor, supernatant discarded again and pellet resuspended in $250 \mathrm{ml}$ ice cold $0.1 \mathrm{M} \mathrm{CaCl} 2$ and stored on ice for 6 hours, then centrifuged at $8000 \mathrm{rpm}$ for $8 \mathrm{~min}$ at $4^{\circ} \mathrm{C}$. Resuspended pellet in $43 \mathrm{ml}$ of ice cold $0.1 \mathrm{M} \mathrm{CaCl} 2$ with $7 \mathrm{ml}$ sterile glycerol. At last distributed suspension of competent cells into convenient aliquots $(0.2 \mathrm{ml})$ in cold Eppendorf tubes and Frozen and store at $-70^{\circ} \mathrm{C}(11)$.

Plasmid transformation: 50ng of plasmid consortium was added to $300 \mu$ l of thawed competent cells E.coli ATCC 25922 in ice. The suspension immediately placed on ice for 30 minutes and then tubes were placed in $42^{\circ} \mathrm{C}$ water bath for $2 \mathrm{~min}$ (heat shock).The mixtures were transferred to $1 \mathrm{~mm} \mathrm{LB}$ medium, and incubated at $37^{\circ} \mathrm{C}$ with shaking, for 1 hour.Then streaked out $50 \mu 1$ of transformed cells onto LB agar plates containing ampicillin antibiotic and incubated at $37^{\circ} \mathrm{C}$ for 24 hours (11). In this section digested DNA was used as negative control .

Resistance pattern of transformed cells: Resistance patterns were determined by the disc diffusion test methodology, with discs containing 10 different antimicrobial agents as : ampicillin $(10 \mu \mathrm{g})$, co-trimoxazole $(25 \mu \mathrm{g})$, gentamycin $(10 \mu \mathrm{g})$, ciprofloxacin $(10 \mu \mathrm{g})$, cefotaxime $(30 \mu \mathrm{g})$, ceftazidime $(30 \mu \mathrm{g})$, tetracycline $(30 \mu \mathrm{g})$, tobramycin
$(10 \mu \mathrm{g}), \quad$ amoxicillin $(10 \mu \mathrm{g}), \quad$ amikacin $(30 \mu \mathrm{g})$, and E.coli ATCC 25922 was used as negative control (10).

\section{Statistical analysis}

For the statistical analyses, the statistical software SPSS version 18 for Windows (SPSS Inc., Chicago, IL) was utiᄀlized. Continuous variables were described as mean \pm standard deviation (SD) and compared with standard student t test, or and calculates median range. All the tests were two-tailed and $\mathrm{P}<0.05$ was considered statistically significant (9).

\section{Results}

Identification of isolates: In this study, totally 200 samples were collected from patients; those were primary positive culture by urine culture. The most common isolate was E.coli $85(42.5 \%)$, followed by Proteus species 25(12.5\%), Pseudomonas species 21(10.5\%), Klebsiella species 20(10\%), Citrobacter species 18(9\%), Staphylococcus aureus 12 (6\%), Entrobacter species 11(5.5\%), coagulasenegative staphylococcus 5 (2.5\%), and Providencia 3(1.5\%). Out of 120 samples, $(60 \%)$ were taken from females and 80(40 $\%)$ from male patients (Figure1). Differential and serological test results showed that of the 25 Proteus isolated, 18 strains $(72 \%)$ were Proteus mirabilis, followed by Proteus vulgaris 6 strains $(24 \%)$ and 1 strain (4\%) Proteus rettgeri were identified.

Antibiotic susceptibility profiles and distribution of MICs of different antibiotics: Table1 shows the antibiotic resistant pattern of Proteus isolates to 10 antibiotics, the isolates showed high frequency of antibiotic resistance against ampicillin (100\%) and low frequency of antibiotic resistance against amikacin with $(16 \%)$. The patterns of MICs of 10 antibiotics on the Proteus isolates were determined with concentrations varying from $32 \mu \mathrm{g} / \mathrm{ml}$ to $64 \mu \mathrm{g} / \mathrm{ml}$ as indicated in Table 1. 
Table1. Antibiotic resistant pattern and MIC pattern of Proteus isolates.

\begin{tabular}{lrrrrrrrrrr}
\hline Antibiotic & \multicolumn{1}{c}{ TS } & TOB & \multicolumn{1}{c}{ GN } & \multicolumn{1}{c}{ AK } & CIP & TE & CTX & CAZ & AMX & AMP \\
\hline Proteus & 56 & 48 & 52 & 16 & 32 & 80 & 40 & 48 & 80 & 100 \\
MIC $(\mu \mathrm{g} / \mathrm{ml})$ & $>32$ & 32 & $>32$ & 64 & 32 & $>64$ & 32 & $>32$ & $>64$ & 128 \\
\hline AMP
\end{tabular}

AMP: Ampicillin, AMX: Amoxicillin, CAZ: Ceftazidime, CTX: Cephotaxime, TE: Tetracycline, CIP: Ciprofloxacin, AK: Amikacin, GN: Gentamycin, TOB: Tobramycin, TS: Co-trimoxazole.

\section{Resistant pattern conferred by plasmid} to E.coli ATCC 25922: Results of transformant isolates showed that, more than of $66.6 \%$ of proteus isolates harbored one or more than one transformable plasmid, and resistant to ampicillin, amoxicillin, gentamycin, ciprofloxacin, cefotaxime and ceftazidime transformed in all isolates $(100 \%)$ due to presence of plasmid. The resistance to amikacin, tobramycin and tetracycline was transferred in $88 \%, 48 \%$ and $66.6 \%$ of isolates due to presence of plasmids with molecular weight range of $4.8 \mathrm{~kb}, 5.2 \mathrm{~Kb}$ and higher than it (Figures 1 and 2).

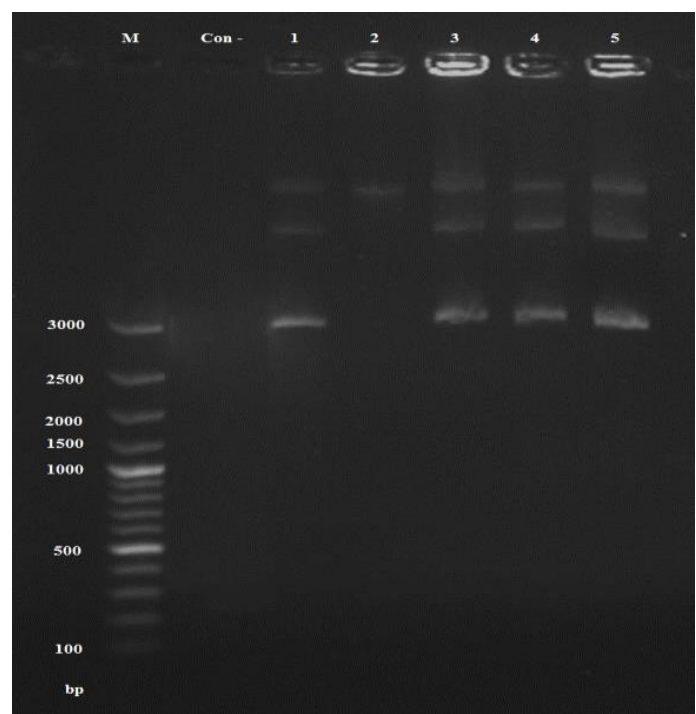

Figure 1. Electrophoresis of plasmid DNA isolated from Proteus isolates. M: DNA ladder, Con- : negative control (E. coli ATCC 25922). Rows (1, 2, 3, 4, and 5) are clinical samples.

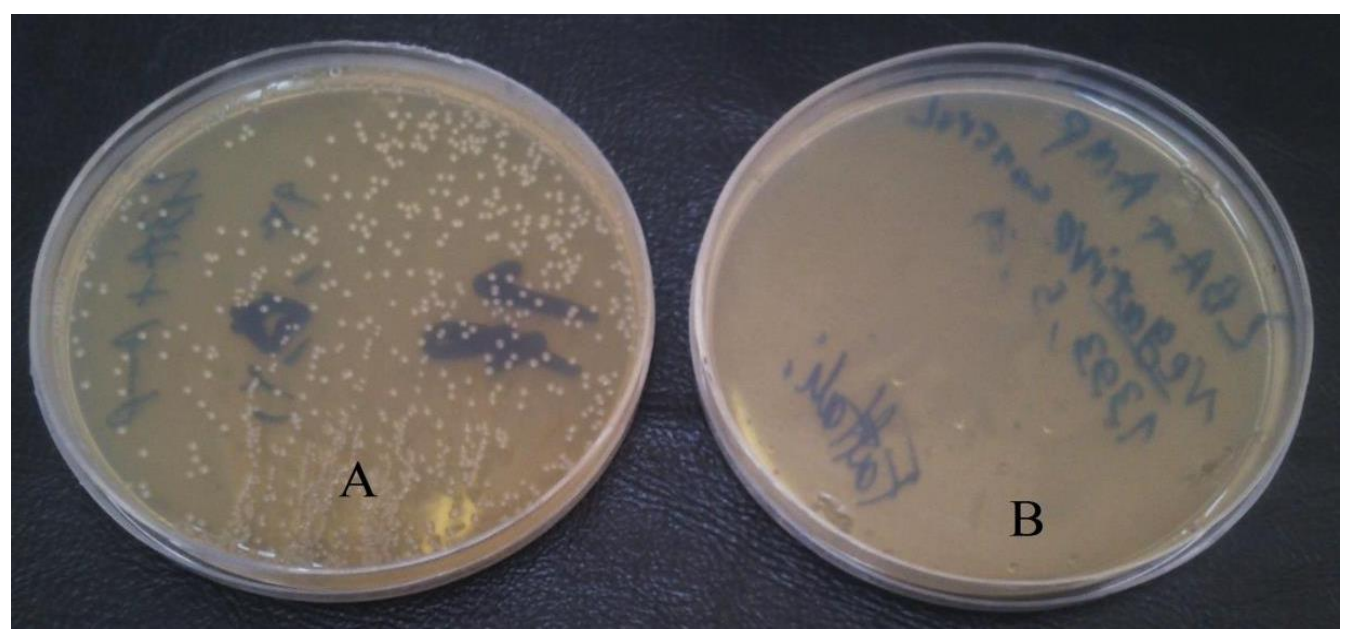

Figure 2. Plasmid transformation to the competent E.coli ATCC 25922. A: Transformed colonies (competent E.coli ATCC 25922) in the Luria-Bertani Agar (LBA) medium complemented by antibiotic ampicillin. B: observation growth inhibition E.coli ATCC 25922 (negative standard species) in the Luria-Bertani agar (LBA) containing antibiotic. 


\section{Discussion}

In the present study, out of 200 samples were studied, and 25 (12.5\%) of Proteus bacteria were isolated from patients suffered from urinary tract infection and $66.6 \%$ of these isolates were consist of plasmid that mediated antibiotic resistant .In a study conducted by Orhue, O.Phillips (2014) in Nigeria, among all bacteria isolated from patients with urinary tract infection, Proteus strains were known as the causes of $14.5 \%$ of these infections and antimicrobial susceptibility pattern of this study was similar to our data, however they did not perform molecular analysis of these strains (12). In other study performed by Okesola AO, and Adeniji TW (2010), they evaluated 50 different clinical Proteus isolates, that, their antibiogram profile is in agreement with our study (13).Chaudhary NK and Morthys SM (2015), in India reported that, Staphylococcus aureus those, causes urinary tract infection acquired resistant to methicillin and vancomycin via plasmid (14). Adeniyi BA (2006), showed that the rate of resistance to ampicillin, cotrimoxazole, gentamycin, ciprofloxacin and tetracycline were $94.2 \%, 84 \%, 84.6 \%$, $50 \%$, and $100 \%$, respectively. The result of this study is in agreement with our data (15), Only 9 out of 18 (50\%) of P. mirabilis isolates were harbored plasmids. In the present study, $66.6 \%$ (6 isolates) of plasmidcontaining P. mirabilis isolates were able to transfer antibiotic resistance to the standard E.coli ATCC 25922 which is in agreement

\section{References}

1. Rozalski A, Sidorczyk Z, Kotelko K. Potential virulence factors of Proteus bacilli. Microbiol Mol Biol Rev. 1997; 61(1):65-89.

2. Warren JW, Tenney JH, Hoopes JM, Muncie HL, Anthony WC. A prospective microbiologic study of bacteriuria in patients with chronic in dwelling urethral catheters. J Infect Dis. 1982; 146(1):719-23. with the results from Makled et al, and Bonnet et al $(16,17)$. The resistant to amoxicillin, ampicillin, gentamycin, tobramycin, amikacin, co-trimoxazole, cefotaxime, ceftazidime ciprofloxacin and tetracycline was transferred in $100 \%$ of isolates due to presence of plasmids with molecular weight 180,170 and $25 \mathrm{~Kb}$, which is in disagreement with the results of this study (18). Neuwirth et al, (2001), reported that resistance to $\beta$-lactams was cotransferred with resistance to aminoglycosides (amikacin, Kanamycin and tobramycin), sulphonamides and chloramphenicol (19). In conclusion, indiscriminate use of antibiotics has led to selection of resistant strain with $\mathrm{R}-$ plasmids transferable between enteric bacteria by transformation and this resistant bacterium may disseminate among individuals. According to this study it's necessary to determine the antibiotic susceptibility and plasmid profiles of Proteus mirabilis isolated from urinary tract infections in order to provide proper treatment, this will prevent their dissemination and reduce the risk of urinary tract infection complication.

\section{Acknowledgements}

This study was supported by University of Ilam. Authors are thankful to the Department of Biology Research Center, Ilam University, Ilam, Iran.

3. Panday J.K, Narayan A, Tyagi Sh. Prevalence of proteus species in clinical sample, antibiotic sensitivity pattern and ESBL production. Int $\mathbf{J}$ Curr Microbiol Appl Sci. 2013; 2(10)25361.

4. Mariotte S, Nordmann PR, Nicolas MH. Extended-Spectrum B-lactamase in Pr.mirabilis. J Antimicrob Chemothr. 1994; 33(1):925-35. 
5. Gutmann L. Cross-resistance to nalidixic acid, imethoprim and chloramphenicol associated with alteration in the outer membrane of Klebseilla, Enterobacter and seratia. J Infect Dis. 1985; 154(4):501-7.

6. Mohamed B, Khalid Z, Jean DP, Gros C, Hamid A, Naima E, et al. Plasmidmediated quinolone resistance in expanded spectrum beta lactamase producing enterobacteriaceae in Morocco. J Infect Dis. 2010; 12(4): 779-803.

7. Thavasi R, Aparnadevi K, Jayalaks S, Balasubramanian T. Plasmid mediated antibiotic resistance in marine bacteria. J Environ Biol. 2007; 28(3): 617-21.

8. Rostamzad A, Rostamneia N, Pourahmad F. Determination of vancomycin and methicillin resistant in clinical isolates of Staphylococcus aureus in Ilam hospitals using PCR. J Bas Res Med Sci.2016; 3(3):1-6.

9. Karimeian M, Rostamzad A, Shoaei P. Extended spectrum $\beta$-lactamaseproducing strains of Escherichia coli in hospitalized children in Isfahan Iran. Avicenna J ClinMicrob Infec. 2015; 2(3):1-5.

10. CLSI. Performance Standards for Antimicrobial Susceptibility Testing; Twenty-Fourth Informational Supplement. 2014; 34(1):2-230.

11. Sambrook J, Russell DW. Molecular cloning, a laboratory manual. Cold Spring Harbor Laboratory Press, New York; 2001. pp: 370-380.

12. Philips OO. Prevalence of uropathogenic bacterial isolates from urinary tract infections: A case study of university of Benin teaching hospital,
Benin City, Nigeria. Int $\mathrm{J}$ Microbiol Appl. 2014; 1(2):18-22.

13. Okesola AO, Adeniji TW. Pattern of extended spectrum beta-lactamases production among clinical isolates of Proteus species in western Nigeria. World J Med Sci. 2010; 5(4):94-7.

14. Chaudhary NK, and Murthys M. Extended Expectrum beta-lactamase in uropathogen. Asian J Pharm Clin Res. 2013; 6(3):1-4.

15. Adeniyi BA, Amajoyi CC, Smith SI. Plasmid profile of multidrug resistant local uropathogenic E.coli, klebsiella species, proteus species and Pseudomonas spp. J Biol Sci. 2006; 6(3):527-31.

16. Makled A, Alghamdi A. Surveillance of aminoglycosides resistance among Proteus mirabilis isolates from different units in Jeddah Hospitals, Saudi Arabia. Egyptian J Med Microbiol. 2006; 15(2): 337-51.

17. Bonnet R, De Champs C, Sirot D, Chanal C, Labia R, Sirot J. Diversity of TEM Mutants in Proteus mirabilis. Antimicrob Agents Chemoth. 1999; 43(11): 2671-77.

18. De Champs C, Monne C, Bonnet R, Sougakoff W, Sirot D, Chanal C, et al. New TEM variant (TEM-92) produced by Pr.mirabilis and Providencia stuartii isolates. Antimicrob Agents Chemothr. 2001; 45(1):1278-80.

19. Neuwirth C, Madec S, Siebor E, Pechinot A, Duez J, Pruneaux M, et al. TEM-89 B-lactamase produced by a Pr. Mirabilis clinical isolate: New complex mutant (CMT3) with mutations in both TEM-59 (IRT-17) and TEM-3. Antimicrob Agent Chemoth. 2001; 45(12):3591-94. 